\title{
The WNT antagonist Dickkopf2 promotes angiogenesis in rodent and human endothelial cells
}

\author{
Jeong-Ki Min, ${ }^{1,2}$ Hongryeol Park, ${ }^{1}$ Hyun-Jung Choi, ${ }^{1}$ Yonghak Kim, ${ }^{1}$ Bo-Jeong Pyun, ${ }^{1,3}$ \\ Vijayendra Agrawal, ${ }^{1}$ Byeong-Wook Song, ${ }^{4}$ Jongwook Jeon, ${ }^{5}$ Yong-Sun Maeng, ${ }^{1}$ \\ Seung-Sik Rho, ${ }^{1}$ Sungbo Shim, ${ }^{6}$ Jin-Ho Chai, ${ }^{1}$ Bon-Kyoung Koo, ${ }^{7}$ Hyo Jeong Hong, ${ }^{2}$ \\ Chae-Ok Yun, ${ }^{8}$ Chulhee Choi, ${ }^{5}$ Young-Myoung Kim, ${ }^{9}$ Ki-Chul Hwang, ${ }^{4}$ and Young-Guen Kwon \\ ${ }^{1}$ Department of Biochemistry, College of Life Science and Biotechnology, Yonsei University, Seoul, Republic of Korea. \\ ${ }^{2}$ Therapeutic Antibody Research Center, Korea Research Institute of Bioscience and Biotechnology, Daejeon, Republic of Korea. \\ ${ }^{3}$ College of Pharmacy and Division of Life Science and Pharmaceuticals, Ewha Womans University, Seoul, Republic of Korea. \\ ${ }^{4}$ Cardiovascular Research Institute, Yonsei University College of Medicine, Seoul, Republic of Korea. ${ }^{5}$ Cell Signaling and Bioimaging Laboratory, \\ Department of Bio and Brain Engineering, Korea Advanced Institute of Science and Technology (KAIST), Daejeon, Republic of Korea. \\ ${ }^{6}$ Department of Biological Science, Sookmyung Women's University, Yongsan-Ku, Seoul, Republic of Korea. ${ }^{7}$ Department of Biological Sciences, \\ Seoul National University, Silim-dong, Gwanak-gu, Seoul, Republic of Korea. ${ }^{8}$ Brain Korea 21 Project for Medical Science, \\ Institute for Cancer Research, Yonsei Cancer Center, Yonsei University College of Medicine, Seoul, Republic of Korea. \\ ${ }^{9}$ Vascular System Research Center, Kangwon National University, Kangwon-Do, Republic of Korea.
}

\begin{abstract}
Neovessel formation is a complex process governed by the orchestrated action of multiple factors that regulate EC specification and dynamics within a growing vascular tree. These factors have been widely exploited to develop therapies for angiogenesis-related diseases such as diabetic retinopathy and tumor growth and metastasis. WNT signaling has been implicated in the regulation and development of the vascular system, but the detailed mechanism of this process remains unclear. Here, we report that Dickkopf1 (DKK1) and Dickkopf2 (DKK2), originally known as WNT antagonists, play opposite functional roles in regulating angiogenesis. DKK2 induced during EC morphogenesis promoted angiogenesis in cultured human endothelial cells and in in vivo assays using mice. Its structural homolog, DKK1, suppressed angiogenesis and was repressed upon induction of morphogenesis. Importantly, local injection of DKK2 protein significantly improved tissue repair, with enhanced neovascularization in animal models of both hind limb ischemia and myocardial infarction. We further showed that DKK2 stimulated filopodial dynamics and angiogenic sprouting of ECs via a signaling cascade involving LRP6mediated APC/Asef2/Cdc42 activation. Thus, our findings demonstrate the distinct functions of DKK1 and DKK2 in controlling angiogenesis and suggest that DKK2 may be a viable therapeutic target in the treatment of ischemic vascular diseases.
\end{abstract}

\section{Introduction}

Angiogenesis, the formation of new blood vessels from a preexisting vascular bed, is essential for embryonic development as well as many pathophysiological processes in adult life, including wound healing, diabetic retinopathy, tumor growth, and metastasis (1-3). During angiogenesis, specialized ECs located at the vascular front undergo dynamic and coordinated phenotypic alterations in morphology, cell-to-cell (and/or cell-to-matrix) communication, and proliferation (4-6). These cellular changes are accompanied by the concomitant dynamic regulation of specific gene expression within a developing vessel, which is indispensable for establishing a functional vascular network $(4,5)$.

Numerous studies have identified many genes with localized expression at the vascular front and delineated their specific functions in regulating EC sprouting and remodeling during development of the vascular tree $(4,5)$. VEGF, the most well-characterized angiogenic molecule, has been shown to guide endothelial tip cell

Authorship note: Jeong-Ki Min and Hongryeol Park contributed equally to this work.

Conflict of interest: The authors have declared that no conflict of interest exists. Citation for this article: J Clin Invest. 2011;121(5):1882-1893. doi:10.1172/JCI42556 filopodia via VEGFR2 at the sprouting front $(2,7)$. Receptors of neuronal axon guidance cues such as Unc5b, EphB4, Plexin D1, and Robo4 are also prominently expressed at the vascular front and play significant roles in vessel path finding and sprouting (8-10). Recently, Notch signaling has been shown to be a key player in vascular morphogenesis, particularly in confining tip cell and stalk cell characters, in addition to arterial-venous determination (5). Notch1 binding by Delta-like 4 (Dll4) suppresses tip cell formation (11-13), and blockade of Dll4-Notch1 signaling in mice inhibits tumor growth by increasing the formation of nonproductive vessels with excessive sprouting and many small vessel branches $(14,15)$. Benedito et al. further showed that Jagged1 (Jag1) antagonizes Dll4-Notch signaling in ECs expressing Fringe family glycosyltransferases and promotes angiogenesis in mice (16). The identification and characterization of factors regulating EC type specification and dynamics should be valuable for further understanding of the molecular mechanisms of neovascularization and for establishing new strategies for treating angiogenesis-dependent diseases.

WNT pathways have been widely implicated in regulating the development and maintenance of the vascular system (17). A large number of studies have demonstrated diverse roles of WNT signal- 
A

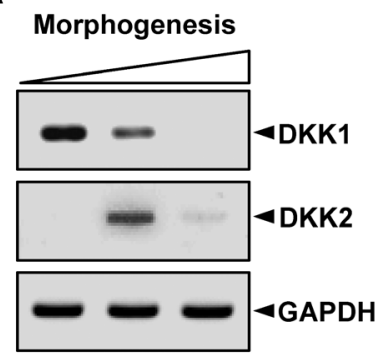

Morphogenesis
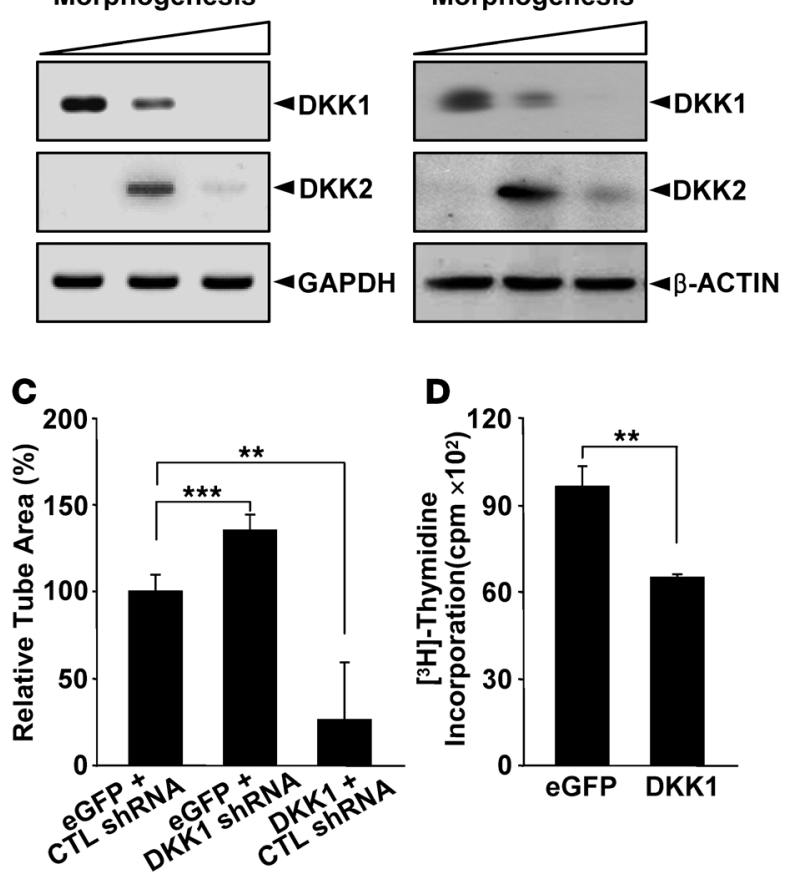

D

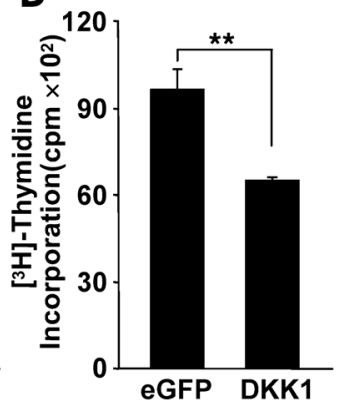

B
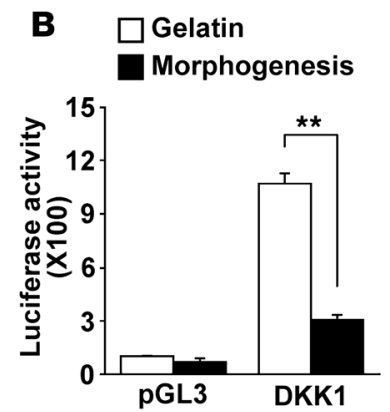

E

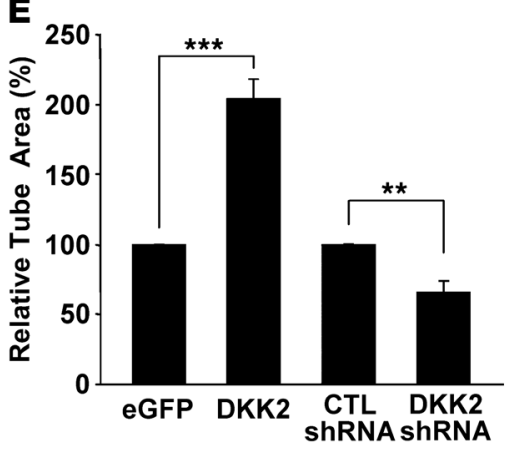

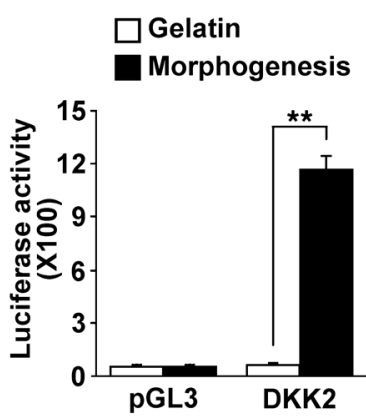

F

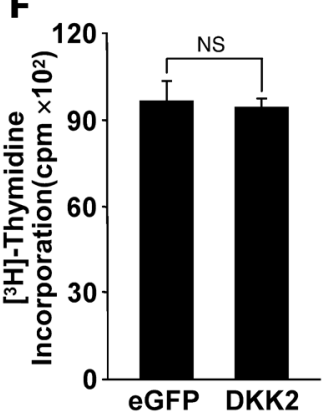

Figure 1

DKK1 and DKK2 reciprocally expressed during endothelial morphogenesis distinctively regulate angiogenesis in vitro. (A) mRNA and protein levels of DKK1 and DKK2 at the same time points $(0.5,8$, and 12 hours) during morphogenesis in Matrigel were measured by RT-PCR (left) and Western blotting (right). (B) Human DKK1 or DKK2 promoter activities were measured by luciferase reporter assay. HUVECs cultured on gelatin-coated plates were transfected and transferred to gelatin-coated plates (gelatin) or Matrigel-coated plates (morphogenesis) 6 hours later. Luciferase reporter activity was measured 16 hours later. Data represent mean \pm SD. (C) HUVECs stably expressing eGFP plus control (CTL) shRNA, eGFP plus DKK1 shRNA, or DKK1 plus control shRNA were established with lentivirus. Stable transfectants were plated on Matrigelcoated plates at a density of $1.5 \times 10^{5} \mathrm{cells} /$ well and incubated for 18 hours. Capillary-like networks, which completely differentiated into tube-like structure, were quantified with Image-Pro Plus software. (D) Proliferative indices of HUVECs transfected with eGFP or DKK1 were assessed by $\left[{ }^{3} \mathrm{H}\right]$-thymidine incorporation assay. (E) HUVECs stably expressing eGFP, DKK2, control shRNA, or DKK2 shRNA. Morphogenesis of the transfectants on Matrigel was analyzed as described in $\mathbf{C}$. $(\mathbf{F})$ Proliferative indices of HUVECs transfected with eGFP or DKK2 were accessed as described in D. Data represent mean \pm SD. ${ }^{* \star} P<0.01 ;{ }^{* *} P<0.001$.

ing in regulating EC functionalities such as proliferation, survival, differentiation, cell junctions, and polarity (18). Indeed, genetic studies have demonstrated that WNT 7b induces hyaloid vessel regression (19) and Norrin-Frizzled4 signaling plays a key role in the vascular development of the eye and ear $(20,21)$. WNT signals are also considered to be orchestrated with other pathways, including Notch and TGF- $\beta$, to regulate vascular morphogenesis (18). However, the function of WNTs and the underlying regulatory pathways in the vasculature remain unclear due to the complexity in spatial expression and interaction of large number of WNTs and their regulatory proteins.

In the present study, we observed that Dickkopf1 (DKK1) and DKK2, originally known as WNT antagonists that bind to LDL receptor-related protein (LRP) $5 / 6$ and inhibit $\beta$-catenin signaling pathways (22-24), are differentially expressed in ECs during morphogenetic differentiation on Matrigel. By employing biochemical and Tg analysis, we demonstrate that DKK1 and DKK2 play opposite functions in regulating angiogenesis. Importantly, DKK2 was found to significantly improve tissue repair with functional neovascularization in ischemic disease models. Furthermore, this study provides what we believe to be novel mechanistic insights regarding DKK2 in stimulating angiogenic sprouting.

\section{Results}

Reciprocal expression of DKK1 and DKK2 during endothelial morphogenesis. To identify factors potentially acting at the sprouting front, we employed Affymetrix oligonucleotide arrays (GEO GSE27160) to isolate genes that reversibly change their expression during in vitro proliferation and morphogenesis of ECs. Interestingly, we detected reciprocal change in the expression of Dickkopf family members DKK1 and DKK2. DKK1 was rapidly downregulated upon induction of morphogenesis on 2D Matrigel, whereas DKK2 was upregulated during this process (Figure 1A). These changes in expression were reversible (Supplemental Figure 1; supplemental material available online with this article; doi:10.1172/ JCI42556DS1) and transcriptionally (Figure 1B) controlled during morphogenesis on Matrigel and proliferation on gelatin.

We further investigated the regulation of DKK1 and DKK2 gene expression. None of the angiogenic factors tested nor hypoxia had an effect on DKK1 and DKK2 expression (Supplemental Figure 2, $\mathrm{A}$ and $\mathrm{B})$. However, DKK2 was sufficiently induced by EC recognition of laminin, a major component of Matrigel, and did not require morphological changes in ECs (Supplemental Figure 2, C-E). In contrast, downregulation of DKK1 was correlated with the induction of morphological changes in ECs (Supplemental Figure 2, 
A
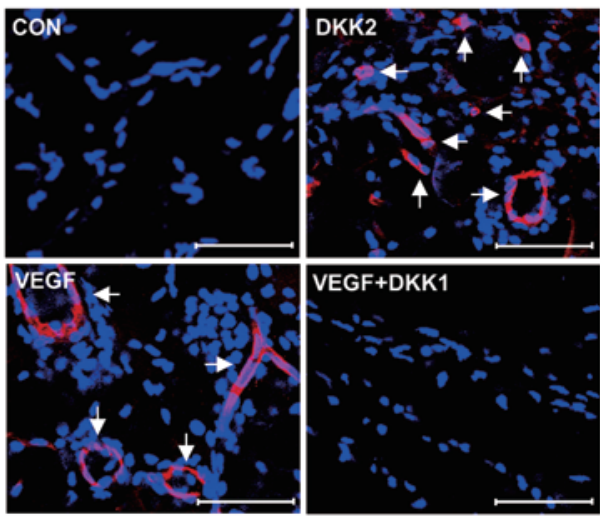

C

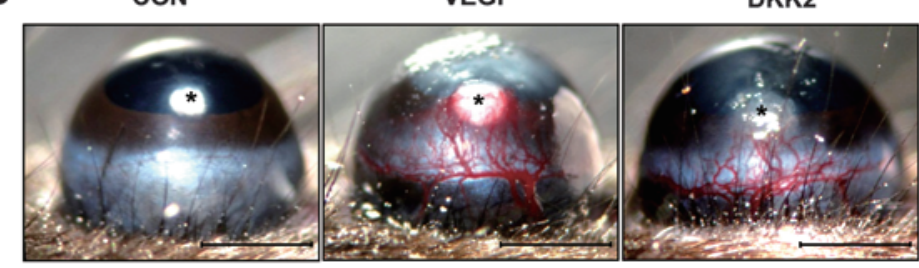

D

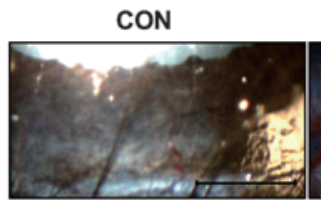

E

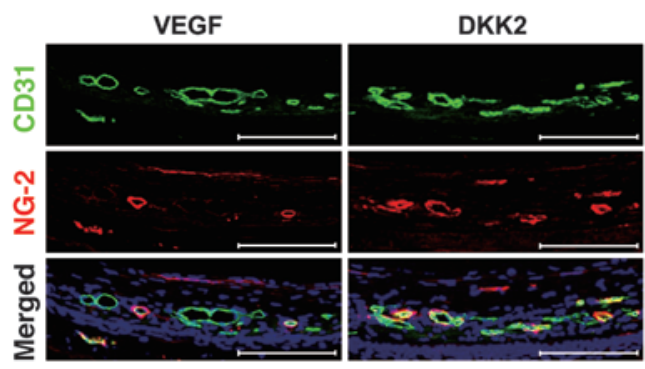

B

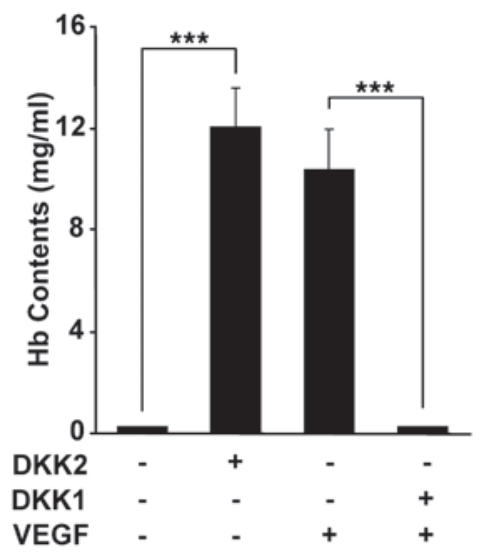

with recombinant DKK1 protein suppressed the formation of EC tube-like structures on 2D Matrigel (Figure 1C and Supplemental Figures 3 and 5). In contrast, overexpression of DKK2 or treatment with recombinant DKK2 protein enhanced the integrity of EC tube-like structures, while knockdown of DKK2 during morphogenesis inhibited it (Figure 1E and Supplemental Figures 4 and 5). In addition, DKK2 treatment of HUVEC-coated beads caused more sprouts of HUVECs compared with controls on fibrin bead assay (Supplemental Figure 6). Interestingly, EC proliferation on gelatin was also significantly inhibited by DKK1 overexpression and increased by $D K K 1$ shRNA transfection (Figure 1D and Supplemental Figure 7). Overexpression of DKK2 had no significant effect on EC proliferation on gelatin (Figure 1F). These results suggest that DKK1 and DKK2 perform opposite functions during angiogenesis in vitro.

DKK2 is a proangiogenic factor in vivo. To evaluate the effects of DKK1 and DKK2 on angiogenesis in vivo, we employed the Matrigel implant assay in mice. DKK2- or VEGF-containing Matrigel plugs were red in color, implying neovascularization (Supplemental Figure 8). The color of Matrigel plugs cotreated with VEGF and DKK1 was similar to that of control-treated plugs (Supplemental Figure 8). Quantification of hemoglobin and CD31 staining of Matrigel plugs consistently indicated that DKK2 significantly increases angiogenesis compared with controls, while DKK1 suppresses VEGF-induced angiogenesis (Figure 2, A and B).

We further examined the structural characteristics of DKK2-induced blood vessels in a mouse cornea pocket assay. As previously demonstrated (25), the growth of VEGF-induced blood vessels was relatively fast, but their structure appeared to be disorganized and leaky (Figure 2C). In contrast, DKK2 induced well-organized vascular networks with distinct vascular tree-like structures (Figure 2C). In addition, Evans blue administration demonstrated that DKK2-induced vessels are

F and G) and was not significantly affected by the recognition of specific ECM components (Supplemental Figure 2C).

Distinct roles of DKK1 and DKK2 during in vitro angiogenesis. We next determined the roles of DKK1 and DKK2 in angiogenesis in vitro. Sustained expression of DKK1 during morphogenesis or treatment less leaky than VEGF-induced vessels (Figure 2D). Compared with VEGF-stimulated capillaries, DKK2-induced vessels consistently showed more coverage of ECs by pericytes and SMCs, which play an important role in vessel maturity and stability (Figure 2, E and F, and Supplemental Figure 9). 
A

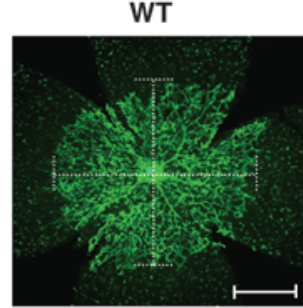

B
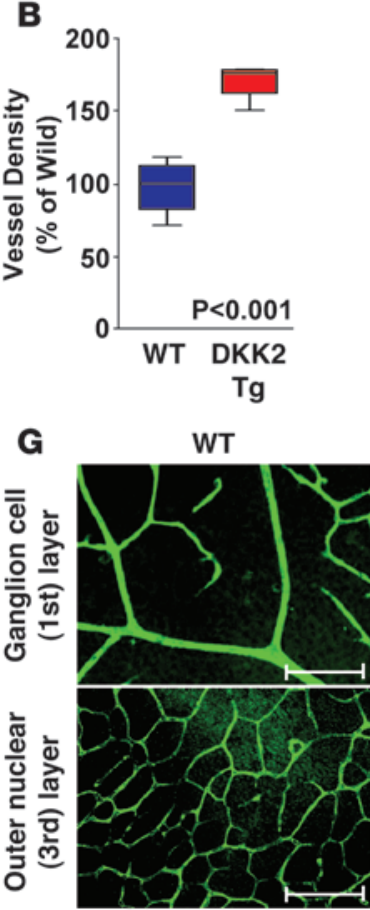

H

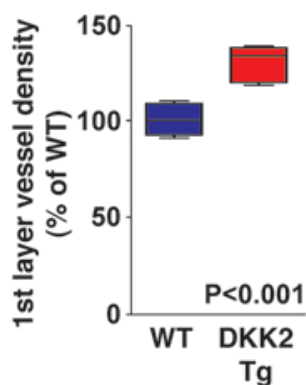

DKK2 Tg

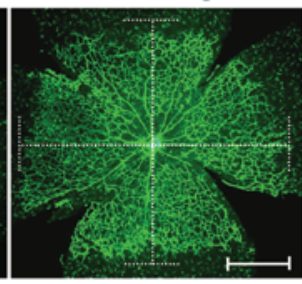

C
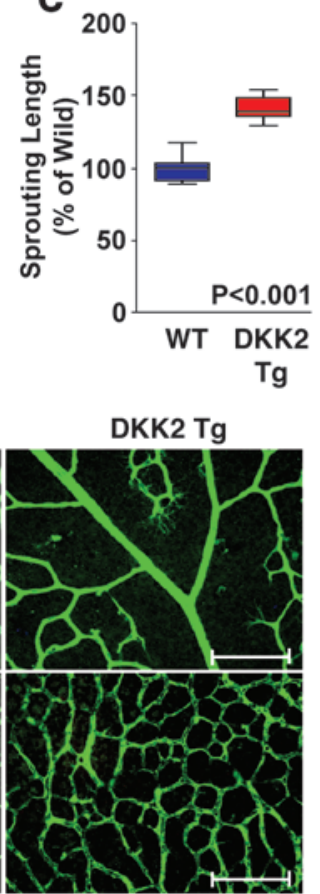

I

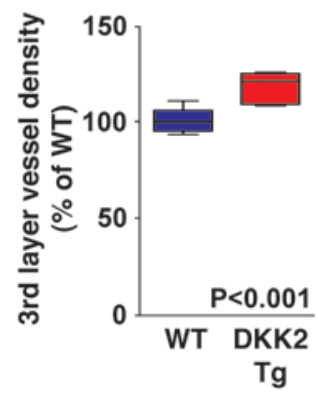

D

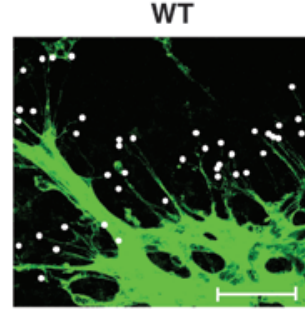

E

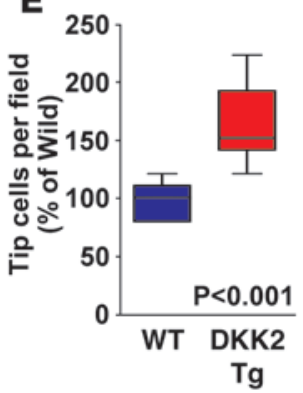

J
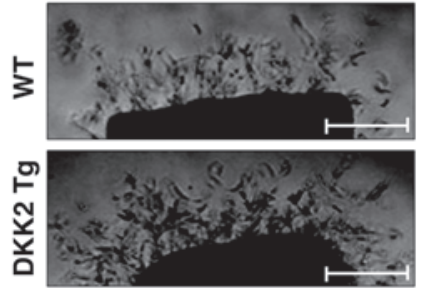

L
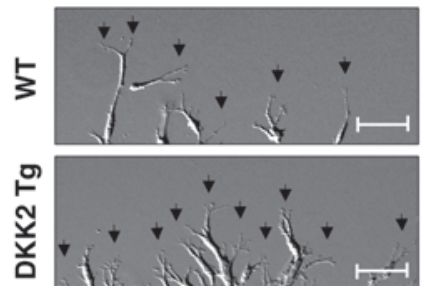

DKK2 Tg

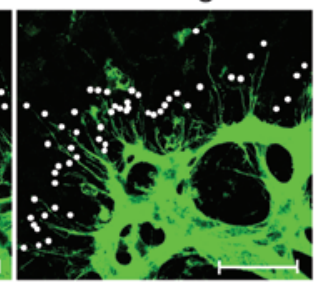

F

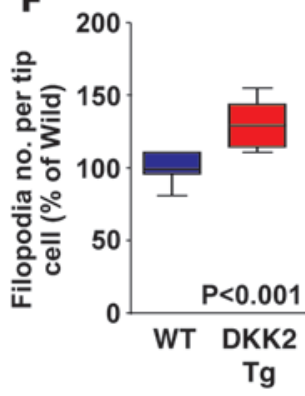

$\mathbf{K}$

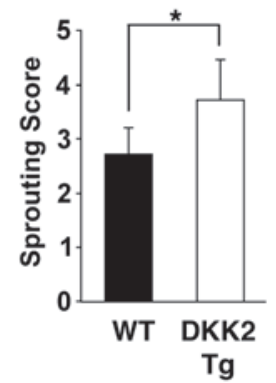

M

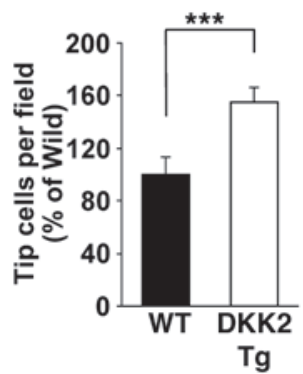

Figure 3

DKK2 Tg mice exhibit increased vessel formation in the retina. (A-F) Isolectin B4 staining of whole-mounted P4 retinas of WT or DKK2 Tg mice $(\mathbf{A}$ and $\mathbf{D})$. White broken lines indicate the range of vessel extension $(\mathbf{A})$. Scale bars: $500 \mu \mathrm{m}$. White dots indicate filopodia extended from tip cells (D). Scale bars: $100 \mu \mathrm{m}$. Quantification of vessel densities (B), sprouting length (C), tip cell number (E), and filopodia (F). (G-I) Isolectin B4 staining of whole-mounted P12 retinas (G). Scale bars: $100 \mu \mathrm{m}$. Quantification of vessel density in the ganglion (first) $(\mathbf{H})$ and the outer nuclear (third) cell layer (I). (J-M) Aortic segments were harvested from WT and DKK2 Tg mice $(n=7$ per group). (J) Endothelial sprouts forming branching cords from the margins of aortic segments were photographed with a phase microscope. Scale bars: $200 \mu \mathrm{m}$. (L) Dynamic movement of endothelial sprouts from the margins of aortic segments was captured as real-time video (see Supplemental Video 1). Scale bars: $40 \mu \mathrm{m}$. Arrows indicate filopodia. Sprouting scores (K) and quantification of tip cell numbers (M). Sprouting scores were scored from 0 (least positive) to 5 (most positive). Data represent mean \pm SD. ${ }^{*} P<0.05 ;{ }^{* \star} P<0.001$. Box indicates $25 \% \sim 75 \%$ value and whisker indicates media value in box plot (B, C, E, F, H, and I). 
A

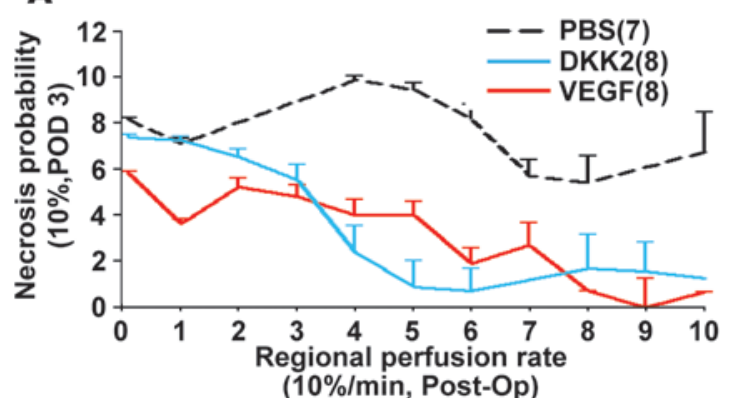

C

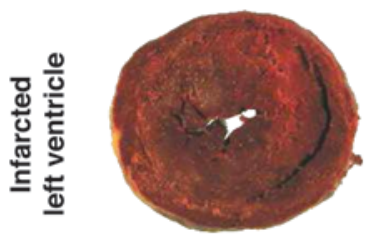

E

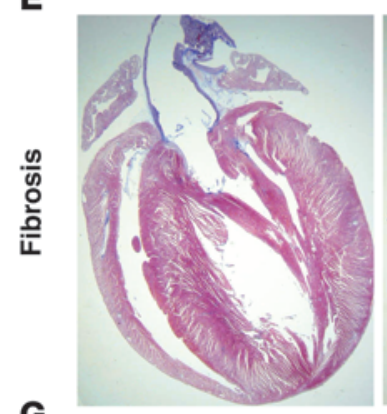

G

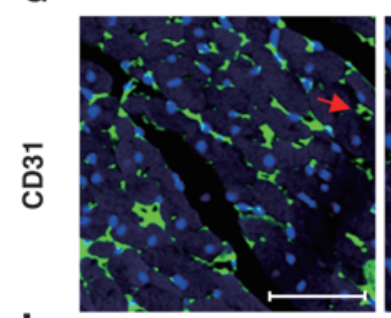

I

를

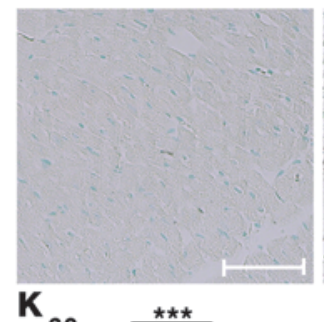

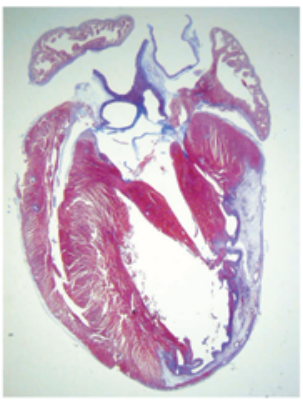
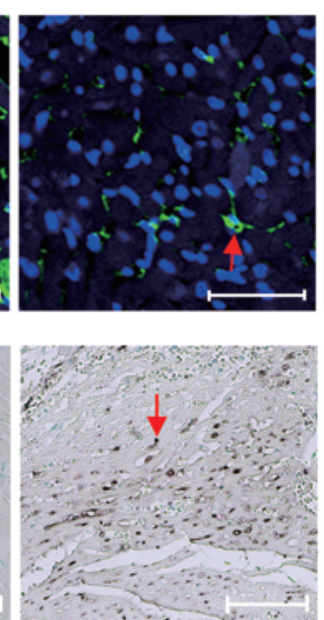

B

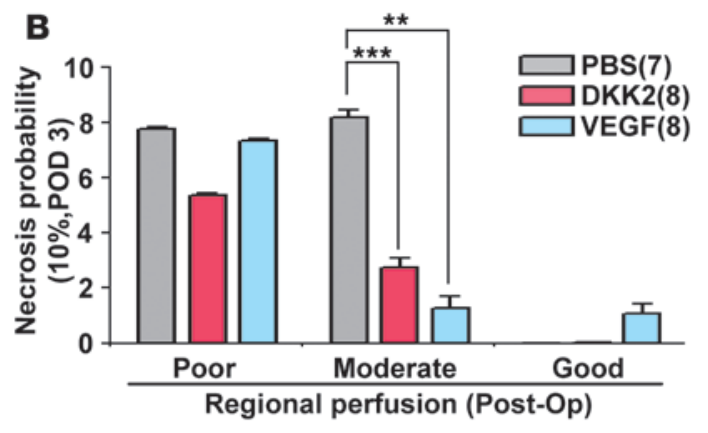

Regional perfusion (Post-Op)
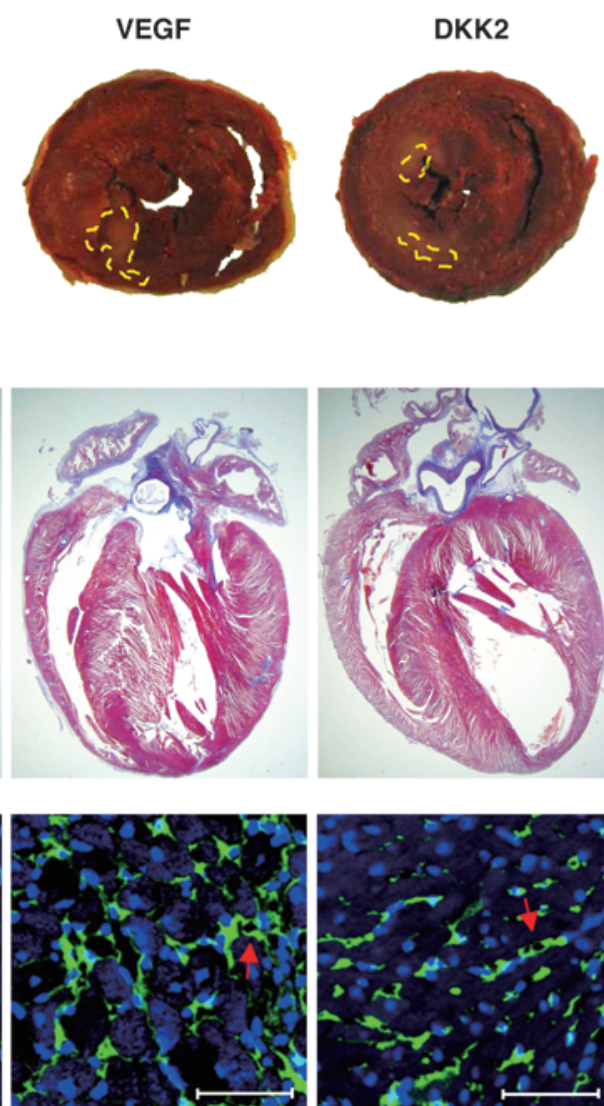

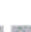
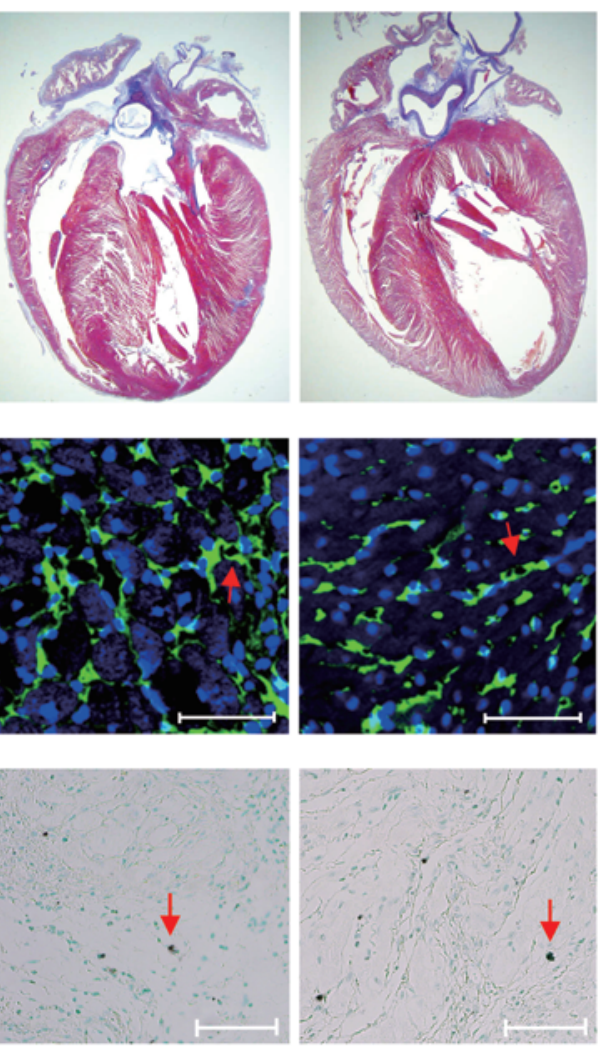

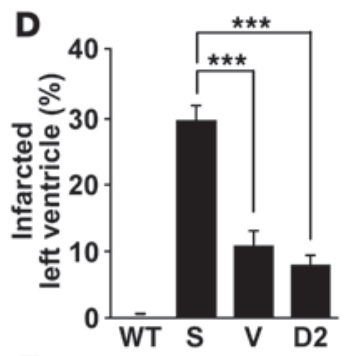

$\mathbf{F}$

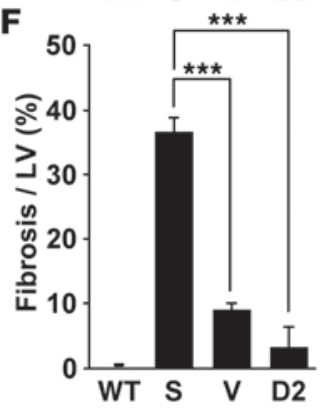

H
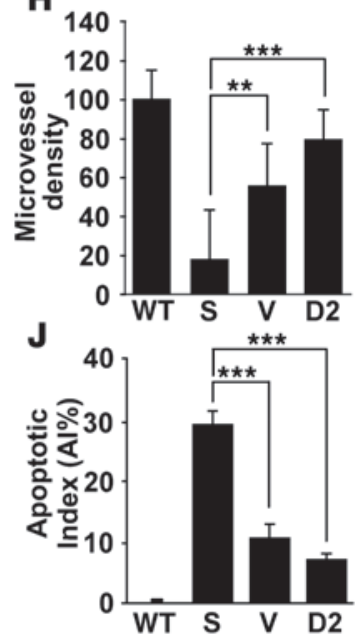
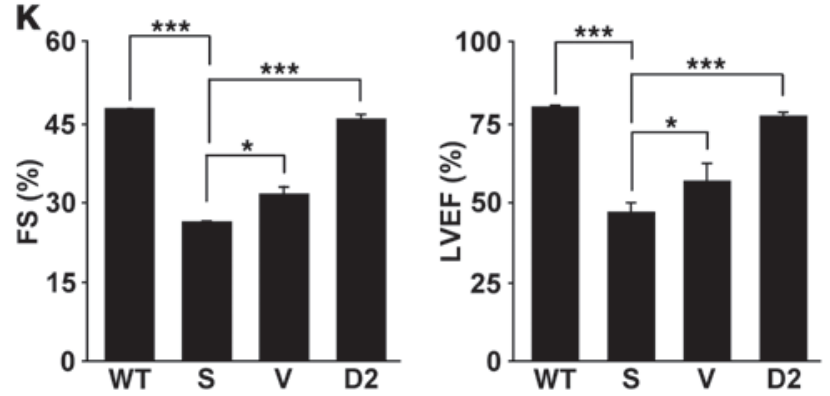


\section{Figure 4}

DKK2 promotes angiogenesis and improves tissue recovery in animal models of hind limb ischemia and MI. (A and B) Intramuscular injection of DKK2 increased blood perfusion and reduced the probability of necrosis in the ischemic hind limb in mice. Tissue perfusion rate $(\% / \mathrm{min})$ was defined as the fraction of blood exchanged per minute in the vascular volume by time-series analysis of indocyanine green dye. Blood perfusion rate of the hind limb was measured at postoperative day 0 (POD 0). Correlation between regional perfusion rates of the ischemic hind limbs at POD 0 and limb necrosis levels at POD 3 was determined. The $x$ axis shows the regional perfusion rate of the ischemic hind limbs (poor perfusion rate: $0 \% \sim 30 \% / \mathrm{min}$; moderate perfusion rate: $30 \% \sim 100 \% / \mathrm{min}$; good perfusion rate: $100<\% / \mathrm{min})$. Normal hind limbs typically demonstrate a perfusion rate above $400 \% / \mathrm{min}$. (C-J) Increase of myocardial repair after DKK2 injection. Myocardial injection of DKK2 decreased the LV infarct size as assessed by TTC staining at 1 week after MI (C and D). Representative images taken from a Masson's trichrome-stained section (muscle is stained red, collagen is stained blue) (E and F). Microvessel staining with CD31 (G) and the TUNEL assay (I) on cardiac muscle tissues. Scale bars: $50 \mu \mathrm{m}$. Quantitative analysis of microvessel density and the TUNEL assay $(\mathbf{H}$ and J). Area with yellow broken lines (C) indicates the infarct region. Red arrows ( $\mathbf{G}$ and $\mathbf{I})$ indicate microvessels and apoptotic cells, respectively. (K) Effective improvement of cardiac function by DKK2 injection. Cardiac functions were measured with 2D conventional parameters: FS and LVEF at 3 weeks after injection of DKK2 into MI rats. FS (\%) = $([$ LVEDD - LVESD]/LVEDD) $\times 100(\%)$. LVEDV $=7.0 \times$ LVEDD3 $/(2.4$ + LVEDD), LVESV $=7.0 \times$ LVESD3/(2.4 + LVESD), and LVEF $(\%)=$ $\left(\right.$ LVEDV - LVESV)/LVEDV $\times 100 .{ }^{*} P<0.05 ;{ }^{* \star} P<0.01 ;{ }^{* \star \star} P<0.001$. S; Sham, V; VEGF, D2; DKK2. Data represent mean \pm SD.

Enhanced angiogenic sprouting and filopodial dynamics in DKK2 Tg mice. To further examine the angiogenic function of DKK2 in vivo, we generated $\mathrm{Tg}$ mice that express $\mathrm{mDKK} 2$ under the control of the EC-specific Tie2 promoter/enhancer (Supplemental Figure 10). In the $3 \mathrm{Tg}$ mouse lines generated, we could not detect significant developmental abnormalities at the embryonic stage or in adults. However, DKK2 Tg embryos generally showed slightly increased capillary density at E9.5 and beyond compared with WT littermates (data not shown). Since the growth rate and patterning of retinal blood vessels during early development are well characterized, we analyzed the retinal phenotype in DKK2 Tg mice. At P4, DKK2 Tg mice displayed increased vascular density and sprouting length in retinal vasculature compared with WT littermates (Figure 3, A-C). The number of tip cells and filopodia were also consistently increased in DKK2 Tg mice (Figure 3, D-F). Ki-67 staining also showed increased endothelial cell proliferation in DKK2 Tg retinas compared with WT littermates (Supplemental Figure 11). The discrepancy between previous in vitro results and current in vivo results may be due to the difference between in vitro culture and in vivo growth conditions. For pericyte recruitment, DKK2 Tg mice did not appear to differ from WT littermates (Supplemental Figure 11). In P12 retinas, the vascular density, internal filopodia, and branching of the ganglion layer (first layer) as well as the vascular plexus in the deeper layer (third layer) were markedly increased in DKK2 Tg mice (Figure 3, G-I, and Supplemental Figure 12). Further, the increase in retinal vascular density was maintained up to 10 weeks after birth (Supplemental Figure 13). In an ex vivo aortic ring assay, the average length and branch number of endothelial sprouts were consistently increased in DKK2 Tg aortas compared with those from WT littermates (Figure 3, J and K, and Supplemental Figure 14). In time-lapse video microscopy recorded over 9 hours, DKK2 Tg aortas showed highly dynamic filopodial protrusion of tip cells (Figure 3, L and M, and Supplemental Video 1).

DKK2 promotes new vessel formation in both hind limb ischemia and myocardial infarction animal models. We next examined the effect of local injection of DKK2 protein on therapeutic neovascularization in a murine model of hind limb ischemia. Hind limb ischemia was induced by ligation and excision of the right femoral artery and vein, resulting in a severe vascular perfusion defect (26). Intramuscular injection of DKK2 resulted in a significant reduction in necrosis compared with ischemic mice treated with PBS (Figure 4, A and B). Indocyanine green (ICG) imaging revealed that blood perfusion was significantly improved at 3 days after surgery in mice injected with DKK2 compared with PBS-injected mice (Figure 4, A and B), consistent with the hypothesis that the reduced necrosis was due to improved neovascularization in the ischemic limb.

We further assessed the therapeutic effect of DKK2 in a rat model of myocardial infarction (MI). One week after MI induction and DKK2 protein injection, the size of the LV infarct was evaluated in the DKK2 and control (sham) groups. Injection of DKK2 protein significantly decreased the infarct size and the degree of fibrosis in the infarct zone compared with sham (Figure 4, C-F). The mean microvessel count per field in the infarcted heart was also higher (Figure 4, G and H), and the incidence of TUNEL-positive myocardial cells was significantly reduced in the DKK2 group compared with sham (Figure 4, I and J).

Changes in cardiac function in DKK2 protein-treated MI animals were measured with transthoracic echocardiography. Echocardiography data (Figure 4K, Supplemental Figure 15, and Supplemental Table 1) showed that DKK2 increased both LV fractional shortening (FS) and LV ejection fraction (EF) compared with sham. Injection of DKK2 or VEGF showed further improvement in systolic performance and cardiac dimensions compared with sham animals. However, cardiac dimensions including LV end diastolic diameter (LVEDD) and LV end systolic diameter (LVESD) were smaller in the DKK2-treated group than in the VEGF-treated group (Supplemental Figure 15 and Supplemental Table 1). The DKK2 group had a higher increase in systolic performance $(16.27 \%$ increment in percentage of FS and $20.5 \%$ increment in percentage of EF) than the VEGF group (Figure 4K, Supplemental Figure 15, and Supplemental Table 1).

$D K K 2$-induced filopodial extrusion of ECs requires $C d c 42$ activation. We next scrutinized the mechanism of action of DKK2 in the vasculature. Previous studies showed that tip cell filopodial extension in the developing retina depends on astrocyte-derived VEGF-A acting directly on tip cells $(7,8)$. However, glial fibrillary acidic protein (GFAP) and VEGF-A mRNA levels, as well as the relative levels of VEGF-A splice isoforms, remained unchanged in DKK2 Tg mice compared with WT mice (Supplemental Figure 16), suggesting a direct action for DKK2 in ECs.

The tips of the sprouts are composed of highly migratory cells with numerous filopodia- and lamellipodia-like processes, which are conferred by the action of small GTPases, such as Cdc42 (27). Therefore, we hypothesized that DKK2 may stimulate tip cell filopodial extension through regulating the activation of Cdc42. In HUVECs cultured on gelatin, overexpression of DKK2 but not DKK1 induced Cdc42 activation (Figure 5A). Consistently, both overexpression of DKK2 and treatment with DKK2 protein induced Cdc42 activation in retinal endothelial cells (RECs) (Sup- 
A

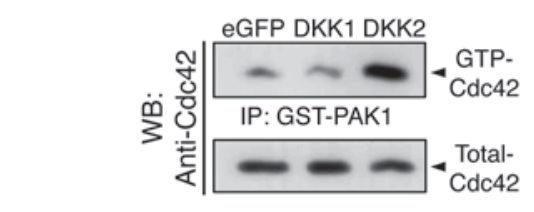

B

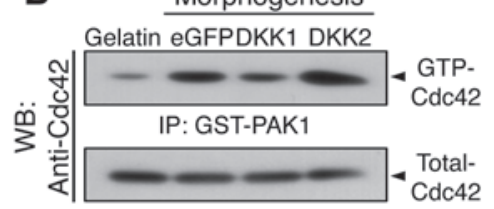

eGFP
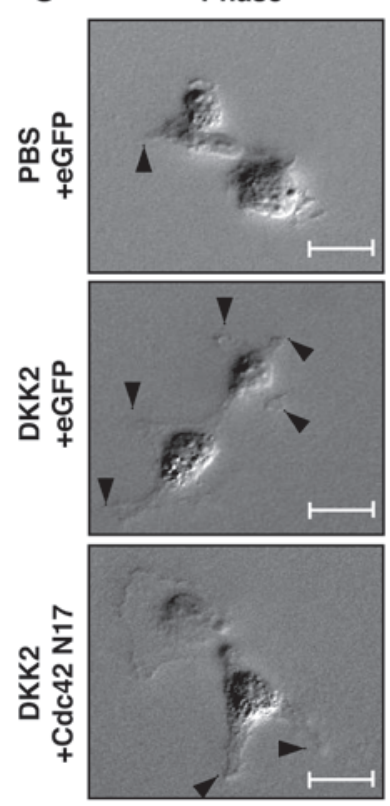

D

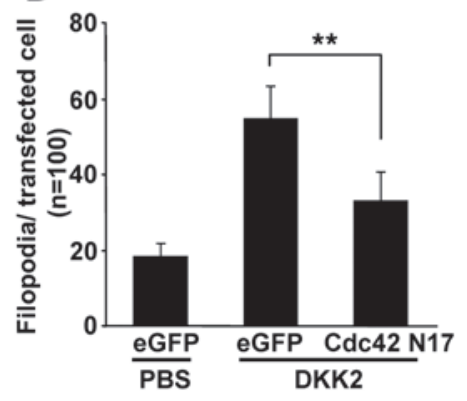

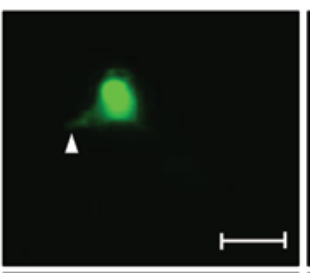
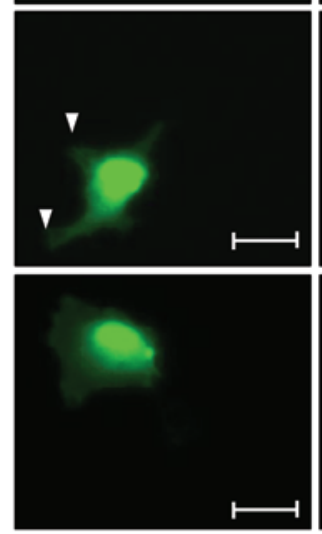

E
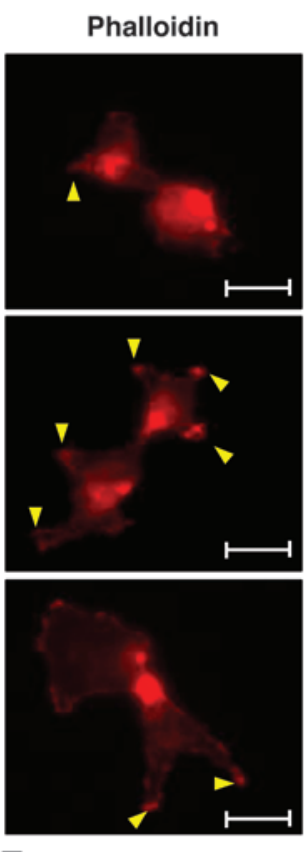
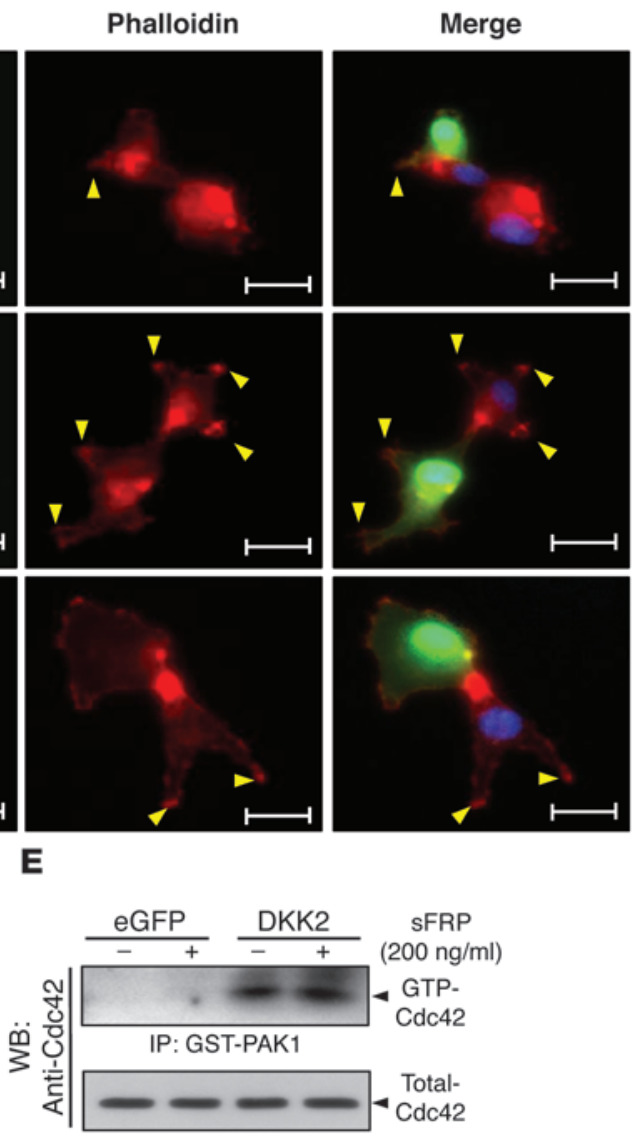

\section{Figure 5}

DKK2 increases filopodial protrusions in a Cdc42dependent manner. (A) HUVECs stably expressing eGFP, DKK1, or DKK2 were analyzed for Cdc42 activities. (B) Stable transfectants were cultured on Matrigel-coated plate (morphogenesis) for 2 hours and Cdc42 activities were measured. (C and D) HUVECs were transiently transfected with expression plasmids encoding eGFP control or eGFP dominant negative mutant of $\mathrm{Cdc} 42$ (Cdc42 N17). After 24 hours, these cells were plated on Matrigel-coated plates and incubated with PBS or DKK2 $(1.5 \mu \mathrm{g} / \mathrm{ml})$ for 2 hours. Then microphotographs were taken (C) and filopodia number was quantified (D). Arrowheads indicate filopodial extension. Data represent mean $\pm S D$. ${ }^{* *} P<0.01$. Scale bars: $20 \mu \mathrm{m}$. (E) HUVECs stably expressing eGFP or DKK2 were incubated with sFRP $(200 \mathrm{ng} / \mathrm{ml})$ for 24 hours and Cdc42 activity was measured. plemental Figure 17). During HUVEC morphogenesis, Cdc42 was spontaneously activated in HUVECs plated on Matrigel and its activation was slightly potentiated in DKK2-expressing HUVECs, but significantly reduced in DKK1-expressing cells (Figure 5B and Supplemental Figure 18). In addition, HUVEC and REC filopodial protrusion was significantly increased by treatment with DKK2 protein at 2 hours compared with controls, and a dominant negative form of Cdc42 blocked DKK2-induced filopodial extensions of HUVECs (Figure 5, C and D, and Supplemental Figures 17 and 19). These results suggest that DKK2 may promote angiogenesis, at least in part, by endowing the dynamics of tip cell structures, which require Cdc42 activation and filopodial protrusion. To identify potential supporting mechanisms of DKK2-mediated Cdc42 activation in ECs, we determined whether the WNT/Frizzled complex or LRP5/ 6 is involved in the signaling events induced by DKK2. Treatment with soluble Frizzled-related protein (sFRP), a decoy antagonist of WNT, did not inhibit DKK2-mediated Cdc42 activation (Figure 5E).
Interestingly, knockdown experiments of LRP5 and LRP6 revealed that LRP6, but not LRP5, was critically involved in DKK2mediated Cdc42 activation, although both LRPs are expressed in ECs (Figure 6A and Supplemental Figure 20, A-C). Consistently, siRNA specific to LRP6 completely blocked DKK2-induced EC morphogenesis, whereas siRNA against LRP5 had no significant effect (Figure 6, B and C, and Supplemental Figure 15, D and E). LRP6 expression was also specifically detected in retinal ECs (Supplemental Figure 21). These results suggest that DKK2 activates the Cdc42 signaling pathway via LRP6 and independent of WNT/ Frizzled signaling.

It has recently been reported that adenomatous polyposis coli (APC) stimulates the guanine nucleotide exchange factor (GEF) activity of APC-stimulated exchange factor 2 (Asef2), a guanine-nucleotide exchange factor specific for Cdc42 (28). Since APC is one of the components working downstream of LRP6, we hypothesized that DKK2 stimulation of LRP6 might induce APC/Asef2 complex formation, resulting in $\mathrm{Cdc} 42$ activation. Indeed, APC and Asef2 inter- 
A

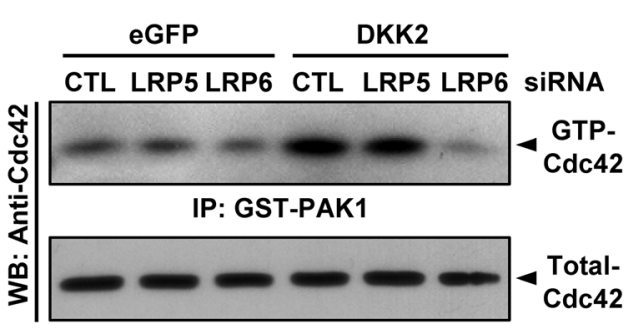

B

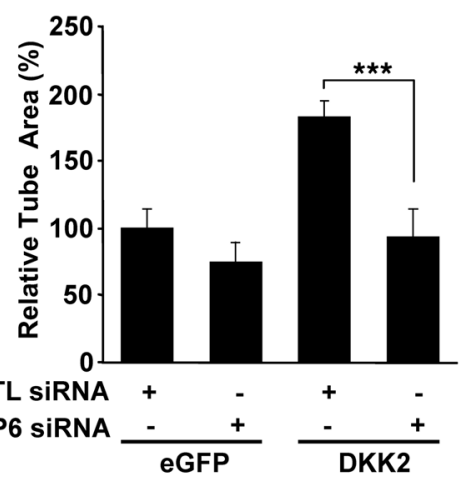

C

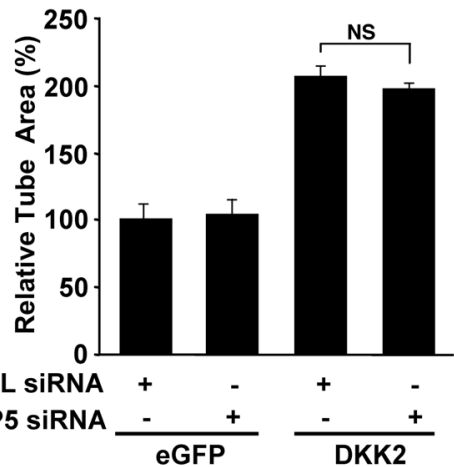

D E

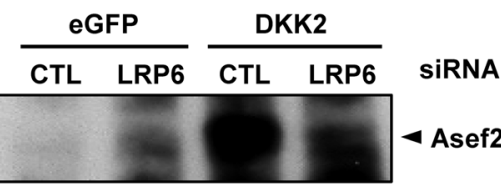

IP: APC
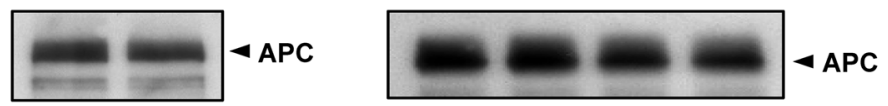

F eGFP

DKK2

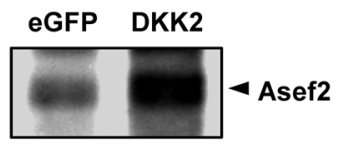

IP: APC
G

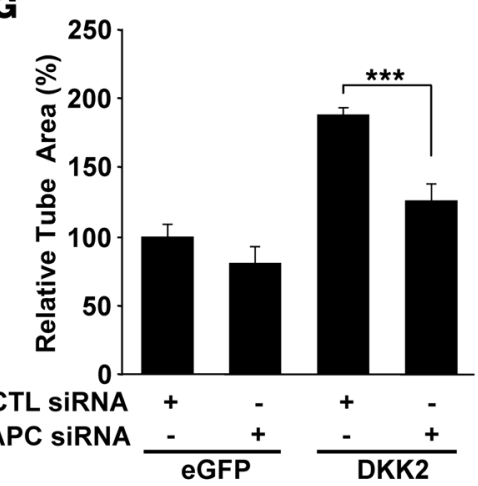

H

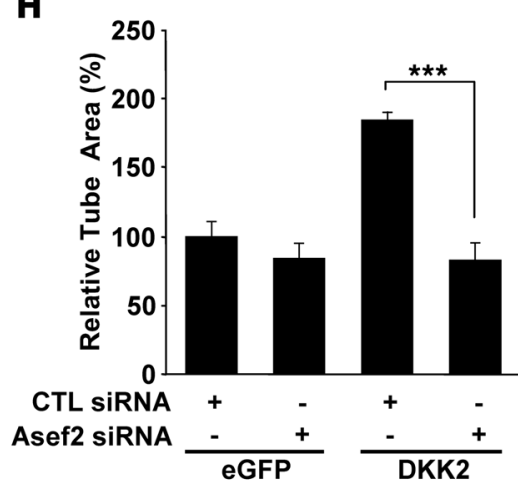

\section{Figure 6}

DKK2-induced Cdc42 activation requires LRP6-mediated APC/Asef2 signaling. (A-C) HUVECs stably expressing eGFP or DKK2 were transiently transfected with control, LRP5-specific, or LRP6-specific siRNA. After 60 hours, Cdc42 activity was measured (A). Cells were plated on Matrigel-coated plates at a density of $1.5 \times 10^{5}$ cells/well and incubated for 18 hours. Microphotographs were taken and capillary-like networks were quantified with Image-Pro Plus software (B and C). (D) Coimmunoprecipitation of APC with Asef2. Lysates were prepared from cells overexpressing eGFP or DKK2, immunoprecipitated with anti-APC antibody, and probed with anti-Asef2 or anti-APC antibodies. (E) eGFP- or DKK2-expressing cells were transiently transfected with control or LRP6-specific siRNA. After 60 hours, cell lysates were subjected to coimmunoprecipitation. (F-H) eGFP- or DKK2-expressing cells were transiently transfected with control, APC-specific, or Asef2-specific siRNA. After 60 hours, Cdc42 activity was measured (F). The cells were plated on Matrigel-coated plates at a density of $1.5 \times 10^{5}$ cells/well and incubated for 18 hours. Capillary-like networks were quantified with Image-Pro Plus software (G and $\mathbf{H})$. Data represent mean $\pm \mathrm{SD}$. ${ }^{* \star} P<0.001$.

action was prominently increased in ECs expressing DKK2 and was blocked by LRP6 siRNA (Figure 6, D and E). Moreover, knockdown of APC or Asef2 inhibited the Cdc42 activation and EC morphogenesis induced by DKK2 (Figure 6, F-H, and Supplemental Figure 22). Taken together, these results indicate that the angiogenic action of DKK2 may be mediated through its cognate receptor LRP6 in ECs and that at least the APC/Asef2 complex lies downstream of LRP6, leading to $\mathrm{Cdc} 42$ activation and stimulation of tip cell dynamics.

\section{Discussion}

In this study, we propose different biological roles of DKK1 and DKK2 in regulating angiogenesis. Expression of DKK1 and DKK2 was reciprocally and specifically regulated depending on the status of ECs, such as proliferation and morphogenetic differentiation. DKK2 promoted angiogenesis, whereas DKK1 suppressed it. DKK1 and DKK2 have similar primary structures and were originally identified as soluble WNT antagonists (29). These proteins regulate various biological functions through inhibition of the WNT signaling pathway (22-24). Interestingly, DKK2 is also suggested to work as an activator depending on cell context $(29,30)$. However, the biological function of DKK2 as an LRP5 or LRP6 agonist in vivo and the underlying signaling mechanism remain to be determined. Our finding that DKK2 promotes angiogenesis provides a new insight into the agonist function of DKK2 in vivo. 
Our data suggest that the angiogenic activity of DKK2 is correlated with activation of EC dynamics. The vascular-specific DKK2 Tg mice exhibited significantly increased vessel branching, EC density, and proliferation, with significantly enhanced numbers of tip cells and filopodia at the vascular front of the retina (Figure 3). Interestingly, these retinal vascular phenotypes of DKK2 Tg mice were comparable to those of Jag1 $\mathrm{Tg}$ mice as described previously (16). Since our study is based on the gain of function, it is limited to arguing whether DKK2 is involved in tip cell and stalk cell specification as Jag1 is. However, it is most likely that the angiogenic sprouting and vascular patterning governed by DKK2 might be correlated with its stimulatory function in tip cell dynamics, as clearly indicated in aortic ring imaging (Figure 3, J-M, and Supplemental Video 1). Our data showed that DKK2 is rapidly induced by EC recognition of laminins, major components of the basement membrane. Notably, it has been shown that laminins were produced by stalk cells and tip cells during sprouting angiogenesis (31) and that laminin-1 induces expression of Jag 1 in ECs (32). We also observed that both Jag1 and DKK2 are induced in a similar way during morphogenesis of HUVECs on Matrigel (data not shown). Thus, the expression pattern and $\mathrm{Tg}$ phenotypes point to a potential relationship between Jag1 and DKK2 in sprouting angiogenesis. Recent in silico analysis suggested that DKK2 is a Notch signaling target in intestinal stem cells (33). However, Notch-response elements were detected in the promoter region of DKK2 of human, chimpanzee, and rat, but not in cow and mouse (33). Thus, it remains unclear whether angiogenic action of DKK2 is functionally correlated with Notch signaling.

This study further provides insight into the mechanism by which DKK2 promotes sprouting angiogenesis. Filopodia extending from tip cells lead the angiogenic sprout by sensing guidance cues and migrating along a specific path in response (7). Previous studies have shown that Rho GTPases represent an important class of molecules involved in vascular morphogenesis $(34,35)$. DKK2, but not DKK1, consistently induced Cdc42 activation in ECs. Although cultured ECs expressed both LRP5 and LRP6, which are potential signaling receptors for DKK2, depletion of LRP6, but not LRP5, resulted in a significant reduction in DKK2-induced Cdc42 activation and EC morphogenesis. LRP5 and LRP6 share 73\% identity in protein sequences but the ligand-binding repeats show only $50 \%$ similarity (36), which suggests that they may not bind ligands with similar affinity. Indeed, it has been shown that LRP6 works differently from LRP5 in the WNT signaling pathway. Overexpression of LRP6, but not LRP5, induces axis duplication in Xenopus (37), and only LRP6 cooperates with several WNT-Frizzled fusion proteins to activate WNT-responsive promoters (38). Similarly, our data suggest that the response of LRP5 and LRP6 to DKK2 in ECs is distinct and LRP6 may act as a cognate DKK2 receptor that mediates Cdc42 activation and angiogenic sprouting.

We further asked how the association of LRP6 with DKK2 activates Cdc42. APC is known to be involved in WNT signaling downstream of LRP6 through its binding to $\beta$-catenin (39). Recent studies have uncovered an additional function for APC, in which it activates Cdc42 via direct binding to Asef2 $(28,40)$. Interestingly, APC/Asef2 complex formation was enhanced by DKK2, and the reduction of APC or Asef2 expression inhibited DKK2-induced Cdc42 activation and EC morphogenesis, suggesting functional significance of the APC/Asef2 system in linking DKK2/LRP6 to Cdc42 activation in ECs. Some WNT members are known to acti- vate Cdc42 via noncanonical pathways, promoting cell polarity (41). However, treatment with sFRP, a decoy antagonist of WNT, did not inhibit DKK2-induced Cdc42 activation (Figure 5E) and DKK2 treatment did not increase $\beta$-catenin-mediated transcription levels (Supplemental Figure 23), suggesting that DKK2 may activate Cdc42 independent of the WNT pathway.

Norrin/LRP5/Fzd4 signaling is well known in regulating retinal angiogenesis. EC-specific knockout mice of Norrin or Fzd4 showed reduced retina vessel growth and endothelial-mural cell interaction (42). However, blocking of Norrin/LRP5/Fzd4 signaling in vitro by Fzd4 CRD IgG did not interrupt Cdc42 activation by DKK2. In addition, Cdc42 activation was not affected by Norrin treatment (Supplemental Figure 24). In summary, CDC42 activation by the DKK2/LRP6 pathway does not seem to be affected by Norrin/LRP5/Fzd4 signaling.

Our data also demonstrate an inhibitory function of DKK1 in angiogenesis with 2 possible mechanisms. First, unlike the WNTindependent mechanism of DKK2 in vascular morphogenesis, DKK1 appears to directly affect WNT signaling in ECs. Previous studies have demonstrated roles for the WNT signaling pathway in angiogenesis and vascular stability $(18,43)$. Signals transmitted from the Frizzled family of receptors upon binding of its ligands, WNT and Norrin, influence angiogenic processes such as EC proliferation and migration (17). Moreover, mice deficient in Lef1 and Ctnnb1, both of which control transcription of target genes of the canonical WNT signaling pathway, displayed significant reduction in vascular density in retinas (44). Our data show that DKK1 inhibits WNT-responsive promoter activity and proliferation of ECs (Figure 1D and Supplemental Figure 25), and endothelium-specific overexpression of DKK1 in mice results in delayed peripheral vascularization and reduced vascular density in retinas (Supplemental Figure 26). Alternatively, DKK1 may counteract DKK2 action through competitive binding to LRP6. This mechanism is supported by our data showing that upregulation of DKK1 antagonizes DKK2-induced angiogenic sprouting and Cdc42 activation (Supplemental Figure 26).

Although knockout of DKK1 and DKK2 showed unique phenotypes in head formation and osteoblast differentiation $(45,46)$, respectively, no obvious vascular phenotype in mutant mice has been reported so far. This may be due to the compensation for DKK1 and DKK2 deficiency by other members of DKK family (47) or other regulatory factors during normal vascular development. And also, considering the complexity and diversity of blood vessels in different organs and pathological states, careful reexamination of vascular phenotypes in DKK-deficient mice may be valuable for further understanding the precise roles of DKKs in the vasculature.

The feature of DKK2-induced vessels, which were structurally organized and well covered by pericytes and SMCs, was different from those induced by VEGF as shown by the corneal assay. DKK2 also provided profound therapeutic effects in 2 ischemic disease models mentioned above. Although the discovery of several angiogenic factors has led to the development of therapeutic strategies for ischemic diseases, the success of therapeutic angiogenesis in clinical trials has been limited due to insufficient efficacy and pronounced adverse effects (48-51). Given that DKK2 is a relatively small and soluble ligand, our finding that DKK2 alone can induce new and functional vessel formation in vivo may provide a novel strategy for developing therapeutic strategies to treat ischemic vascular diseases. 


\section{Methods}

Cell culture. HUVECs were isolated from human umbilical cord veins by collagenase treatment, as described previously (52), and used from passages 2-4. HUVECs were cultured in EC basal medium (EBM) or EC growth medium (EGM, Clonetics) supplemented with 3\% FBS.

In vitro morphogenesis on $2 D$ Matrigel and oligonucleotide microarrays. In vitro morphogenesis was assayed as previously described (53). Briefly, $800 \mu \mathrm{l}$ of growth factor-reduced Matrigel (BD Biosciences) was transferred to a 60- $\mathrm{mm}$ tissue culture well and polymerized for 30 minutes at $37^{\circ} \mathrm{C}$. HUVECs were plated onto the layer of Matrigel at $1 \times 10^{6}$ cells/plate and cultured for $0.5,8$, or 18 hours. At each time point, total RNA was isolated and hybridized to the HG-U133A 2.0 microarray (54675 human genes; Affymetrix). The standard protocol used for sample preparation and microarray processing is available from Affymetrix. Full data sets are available online (Gene expression analysis during morphogenesis of Human umbilical vein endothelial cells; GEO GSE27160).

EC proliferation assay. HUVECs were seeded at $2 \times 10^{4}$ cells/well in gelatin-coated 24-well plates. After 48 or 72 hours, cells were washed twice with M199 and incubated for 6 hours in M199 containing $0.5 \mu \mathrm{Ci} / \mathrm{ml}$ of $\left[{ }^{3} \mathrm{H}\right]$ thymidine (Amersham). High-molecular weight DNAs were precipitated using $10 \%$ trichloroacetic acid at $4{ }^{\circ} \mathrm{C}$ for 30 minutes. After 2 washes with ice-cold $\mathrm{H}_{2} \mathrm{O},{ }^{3} \mathrm{H}$-radioactivity was solubilized in $0.2 \mathrm{~N} \mathrm{NaOH} / 0.1 \%$ SDS and determined by liquid scintillation counter.

In vivo Matrigel plug assay. The Matrigel plug assay was performed as previously described. Briefly, 7-week-old C57BL/6 mice (Orient Co.) were injected subcutaneously with $0.6 \mathrm{ml}$ of Matrigel containing the indicated amount of DKK2, DKK1, VEGF+DKK1, and 10 units of heparin. The injected Matrigel rapidly formed a single, solid gel plug. After 5 days, the skin of the mouse was easily pulled back to expose the Matrigel plug, which remained intact. Hemoglobin was measured by the Drabkin method with Drabkin Reagent Kit 525 (Sigma-Aldrich) to quantify blood vessel formation. The concentration of hemoglobin was calculated from a known amount of hemoglobin assayed in parallel. To identify infiltrating ECs, immunohistochemistry was performed with anti-CD-31 antibody (BD Biosciences).

Mouse corneal pocket assay. Eight-week-old C57BL/6 mice were anesthetized with zoletil $50(15 \mathrm{mg} / \mathrm{kg})$ and lumpun $(5 \mathrm{mg} / \mathrm{kg})$. After 10 minutes, alcaine was dropped into the eye. With a von Graefe cataract knife, a micropocket was made in the cornea. Micropellets $(0.35 \times 0.35 \mathrm{~mm})$ of sucrose octasulfate-aluminum complex (s0652; Sigma-Aldrich) coated with poly2-hydroxyethyl methacrylate (p3932; Sigma-Aldrich) containing $200 \mathrm{ng}$ of VEGF (K0921632; KOMABIOTECH) and $1 \mu \mathrm{g}$ of DKK2 were implanted into the corneal micropocket. The pellet was positioned $0.6-0.8 \mathrm{~mm}$ from the corneal limbus. Tardomyocel-L ointment was applied to the eye after implantation. Eyes were examined with a microscope 7 days after implantation. Cryosections were stained with anti-CD31 (BD Pharmingen) and anti-NG2 (Millipore) antibodies.

Aortic ring assay. Aortas were harvested from 6- to 8-week-old C57BL/6 WT and DKK2 Tg mice. Plates (48-well) were coated with $100 \mu \mathrm{l}$ Matrigel, and after it had gelled, the rings were placed in the wells and sealed in place with an overlay of $40 \mu \mathrm{l}$ Matrigel. EGM was added to the wells in a final volume of $200 \mu \mathrm{l}$ of human endothelial serum-free medium (Invitrogen). On day 5 , cells were fixed and stained with isolectin B4. The assays were scored, double-blinded, from 0 (least positive) to 5 (most positive). Each data point was assayed 6 times. Endothelial sprouts were time-lapse imaged on an Olympus IX81-ZDC inverted fluorescence microscope (Olympus).

Analysis of mouse retinal vasculature. The vascular pattern of dissected mouse retina was analyzed using a modification of a method previously reported (7). Mice were sacrificed by ketamine injection and eyes were enucleated in PBS. The eyes were fixed in 4\% PFA-PBS ( $\mathrm{pH} 7.4$ ) for 1 hour at $4{ }^{\circ} \mathrm{C}$. Retinas were dissected as described (54), postfixed in $70 \%$ ethanol overnight at $4^{\circ} \mathrm{C}$, washed with PBS, and permeabilized with PBS containing $1 \%$ Triton X-100 for 1 hour. Retinas were then incubated in blocking solution for 4 hours at $37^{\circ} \mathrm{C}$, followed by overnight incubation in Alexa Fluor 488-conjugated Isolectin GS-IB 4 solution (Molecular Probes) at $4^{\circ} \mathrm{C}$. After 5 washes in PBS containing 1\% Triton X-100, the retinas were flat mounted on slides using fluorescent mounting medium. Flat-mounted retinas were analyzed by fluorescence microscopy using an Olympus IX81ZDC inverted fluorescence microscope and confocal fluorescent microscope (LSM 510 META; Carl Zeiss).

Cryosection immunofluorescence staining. Tissue was fixed in 4\% PFA-PBS ( $\mathrm{pH} 7.4$ ) overnight at $4^{\circ} \mathrm{C}$ and rinsed with $\mathrm{PBS}$ at room temperature. Tissue was incubated in $15 \%$ sucrose solution overnight at $4^{\circ} \mathrm{C}$ and then transferred to $30 \%$ sucrose at $4^{\circ} \mathrm{C}$ until the tissue sank. All fixation, rinsing, and incubation were done gently. Tissue was infiltrated in OCT embedding medium (Tissue Tek) for 0.5 hours at room temperature before freezing. Tissue was transferred to an embedding mold, which was filled with OCT. The mold was cooled with liquid nitrogen. After the material had frozen, tissue was wrapped in aluminum foil and stored at $-70^{\circ} \mathrm{C}$. Sections (8- to $50-\mu \mathrm{m}$ thick) were cut at $-20^{\circ} \mathrm{C}$, and slides were stored at $-70^{\circ} \mathrm{C}$ until needed. Sections were prefixed in acetone for 0.5 hours at $-70^{\circ} \mathrm{C}$ and then dried briefly until the acetone was removed. OCT was removed with water. Sections were incubated in blocking solution for 4 hours at $37^{\circ} \mathrm{C}$ or overnight at $4^{\circ} \mathrm{C}$, followed by overnight incubation in primary antibody at $4^{\circ} \mathrm{C}$. After 5 washes in $0.3 \%$ Triton X-100 in PBS for 15 minutes each, the sections were incubated in secondary antibody overnight at $4^{\circ} \mathrm{C}$. Before washing, the sections were treated with DAPI $(1 \mu \mathrm{g} / \mathrm{ml})$ and washed 5 more times with $0.3 \%$ Triton X-100 in PBS for 15 minutes each. All antibodies were dissolved in antibody diluent (Dako). Sections were analyzed by fluorescence microscopy using an Olympus IX81-ZDC inverted fluorescence microscope or a confocal microscope (LSM 510 META; Carl Zeiss).

Murine hind limb ischemia model. BalB/cAnNCriBgi-nu nude male mice were obtained from Charles River Japan. All mice were 7-8 weeks (15-20 g) of age at the time of study. Hind limb ischemia was induced by ligation and excision of the right femoral artery and vein under ketamine-xylazine anesthesia. For angiogenic potential studies, mice were divided into 3 groups after induction of ischemia. Mice received intramuscular injection of PBS $(20 \mu \mathrm{l}$ with $0.9 \% \mathrm{NaCl})$ alone as a control, saline solution containing DKK2 $(20 \mu \mathrm{l}$ of $600 \mathrm{ng} / \mu \mathrm{l})$, or saline solution containing VEGF $(20 \mu \mathrm{l}$ of $150 \mathrm{ng} / \mu \mathrm{l})$.

NIR fluorescence imaging. We used customized optical systems for NIR fluorescence imaging, as previously described by Kang et al. (55). Briefly, this system employs a CCD digital camera (PIXIS 1024; Princeton Instruments) with a custom-made 830-nm band-pass filter (Asahi Spectra USA) and 760-nm light-emitting diode arrays (SMC760; Marubeni America). For time-series ICG imaging, mice under ketamine-xylazine anesthesia were injected with an i.v. bolus of ICG $(0.1 \mathrm{ml}$ of $400 \mathrm{mM} / 1$; Sigma-Aldrich $)$ into the tail vein. ICG fluorescence images were obtained in a dark room for 10 minutes at 1 -second intervals immediately after injection. After serial imaging, customized computer programs were used to obtain perfusion maps and necrosis probabilities.

MI model and experimental procedure. MI was induced in 8-week-old Sprague-Dawley male rats (56). Rats were anesthetized with ketamine $(10 \mathrm{mg} / \mathrm{kg})$ and xylazine $(5 \mathrm{mg} / \mathrm{kg})$, and surgical occlusion of the left anterior descending coronary artery was performed with a 6-0 silk suture (Johnson and Johnson). 60 minutes after occlusion, the myocardium was reperfused, and $3 \mu \mathrm{g}$ of protein was injected into 3 sites from the injured region to the border using a Hamilton syringe (Hamilton Co.) with a 30-gauge needle. Throughout the operation, rats were ventilated with $95 \% \mathrm{O}_{2}$ and $5 \% \mathrm{CO}_{2}$ using a Harvard ventilator. Six animals per group were used for morphologic analysis at 1 week after the operation. For functional studies, we performed echocardiography at 3 weeks. To determine infarct size, the 
hearts were removed, perfused with $1 \%$ 2,3,5-triphenyltetrazolium chloride (TTC; Sigma-Aldrich) solution, $\mathrm{pH} 7.4$, at $37^{\circ} \mathrm{C}$ for 20 minutes, and then fixed in $10 \%$ PBS-buffered formalin overnight at $2-8^{\circ} \mathrm{C}$.

Histology and immunohistochemistry of the rat MI model. The heart was excised, fixed with 10\% PBS-buffered formalin for 24 hours, and embedded in paraffin. Sections (5- $\mu \mathrm{m}$ thick) were mounted on gelatin-coated glass slides to allow the use of different stains on sections. After deparaffinization and rehydration, the tissue sections were stained with Masson's trichrome for analysis of fibrosis. For histological analysis, an R.T.U. VECTASTATIN Universal Quick Kit (Vector Laboratories) was used for paraffin sections. Sections were deparaffinized, rehydrated, and rinsed with PBS. Antigen retrieval was performed by microwaving for 10 minutes in $10 \mathrm{mM}$ sodium citrate ( $\mathrm{pH}$ 6.0). Sections were incubated in $3 \% \mathrm{H}_{2} \mathrm{O}_{2}$ to quench endogenous peroxidase activity. Sections were blocked in $2.5 \%$ normal horse serum and incubated in primary antibody (CD31). Biotinylated pan-specific universal secondary antibody and streptavidin/peroxidase complex reagent were used for the heart sections, which were stained with antibody using a DAB substrate kit (Vector Laboratories). Sections were counterstained with $1 \%$ methyl green and dehydrated in 100\% N-butanol, ethanol, and xylene before mounting in VectaMount Medium (Vector Laboratories).

Tissue TUNEL assay. The TUNEL assay was performed according to the manufacturer's instructions (Chemicon International). A positive control sample was prepared from a normal heart section by treating the section with DNase I (10 U/ml, 10 minutes at room temperature). Sections were pretreated with $3.0 \% \mathrm{H}_{2} \mathrm{O}_{2}$, subjected to TdT enzyme at $37^{\circ} \mathrm{C}$ for 1 hour, and incubated in digoxigenin-conjugated nucleotide substrate at $37^{\circ} \mathrm{C}$ for 30 minutes. Nuclei exhibiting DNA fragmentation were visualized by adding 3,3-diaminobenzidine (DAB; Vector Laboratories) for 5 minutes. Finally, sections were counterstained with methyl green and analyzed with light microscopy. For each group, 6 sections were prepared, and 10 different regions were observed per section $(\times 200)$.

Echocardiography. Transthoracic echocardiographic studies were performed by an experienced cardiologist blinded to group assignments, using a GE Vivid Seven ultrasound machine (GE Medical System) with a $10.0-\mathrm{MHz}$ transducer. Rats received general anesthesia and were placed in the left lateral decubitus position. The echo transducer was placed on the left hemithorax, and short axis views were recorded. Two-dimensional images were obtained at midpapillary level (56). M-mode tracing of LV contraction was obtained at the same level as the short-axis view. LVEDD and LVESD were measured with M-mode tracing. Percentage of FS was calculated using the following equation: ([LVEDD - LVESD]/LVEDD) $\times 100(\%)$. LV end diastolic volume (LVEDV) was calculated as $7.0 \times \operatorname{LVEDD}^{3} /(2.4+\mathrm{LVEDD}) ; \mathrm{LV}$ end systolic volume (LVESV) as $7.0 \times \mathrm{LVESD}^{3} /(2.4+\mathrm{LVESD})$; and LVEF as EF (\%) $=($ LVEDV - LVESV $) / L V E D V \times 100$. Two images per view were obtained, and each parameter was measured from 3 consecutive beats per image. Six values of each parameter were obtained and averaged. Echocardiograms were stored digitally and analyzed with EchoPAC with custom 2D strain rate imaging software. More than 3 images were obtained in the short axis view, and the parameters were measured from 3 consecutive beats in each image.

RT-PCR analysis. Total RNA was isolated from HUVECs using a TRIzOL reagent kit. Different amounts of total RNA $(0.5-5 \mu \mathrm{g})$ were amplified with RT-PCR, and the correlation between the amount of RNA used and the level of PCR products obtained from target mRNAs and the internal standard (GAPDH) mRNA was examined. Briefly, cDNA was synthesized from target RNA using $200 \mathrm{U}$ of reverse transcriptase and $500 \mathrm{ng}$ of oligo(dT) primer in $50 \mathrm{mM}$ Tris- $\mathrm{HCl}$ (pH 8.3), $75 \mathrm{mM} \mathrm{KCl}, 3 \mathrm{mM} \mathrm{MgCl}_{2}, 10 \mathrm{mM} \mathrm{DTT}$, and $1 \mathrm{mM}$ dNTPs at $42^{\circ} \mathrm{C}$ for 1 hour. The reaction was stopped by heating at $70^{\circ} \mathrm{C}$ for 15 minutes. A total of $1 \mu \mathrm{l}$ of the cDNA mixture was then used for enzymatic amplification. PCR was performed in $50 \mathrm{mM} \mathrm{KCl}, 10 \mathrm{mM}$ Tris- $\mathrm{HCl}$ ( $\mathrm{pH} 8.3$ ), $1.5 \mathrm{mM} \mathrm{MgCl}_{2}, 0.2 \mathrm{mM}$ dNTPs, $2.5 \mathrm{U}$ of TaqDNA polymerase (Promega), and $0.1 \mu \mathrm{M}$ of each primer for target genes in a DNA thermal cycler (model PTC-200; MJ Research) under the following conditions: denaturation at $94^{\circ} \mathrm{C}$ for 5 minutes for the first cycle and for 30 seconds starting from the second cycle, annealing at $55^{\circ} \mathrm{C}$ for 30 seconds, and extension at $72^{\circ} \mathrm{C}$ for 30 seconds for 25 cycles. Final extension was at $72^{\circ} \mathrm{C}$ for 10 minutes.

The following primer pairs were designed for RT-PCR and synthesized by Bioneer Inc.: mDkk2_A, 5'-CAGAGATGGGATGTGTTGCC-3' and 5'-CCTGATGGAGCACTGGTTTG-3'; mDkk2_B, 5'-GATGGGTTTTGTTGTGCTCG-3' and 5'-ATGTTTCAGGTTCAGGGGGA-3'; mGapdh, 5'-CGCCACAGTTTCCCGGAGGG-3' and $5^{\prime}$-CCCTCCAAAATCAAGTGGGG-3'; DKK1, 5'-CCTGGAGTGTAAGAGCTTTG-3' and 5'-CCAAGAGATCCTTGCGTT-3'; DKK2, 5'-TAGAGATTGAGTTTGAGCCT-3' and 5'-AAAGGGTGGACATAAGAAA-3'; KREMEN2, 5'-CACCGACTGTGACCAGAT- $3^{\prime}$ and 5'-GAGTAGATGACGCCCTGAG-3'; LRP6, 5'-GTCCTTCCACTCATAGGTCA-3' and 5'-GTGGGTAGAGGTGATGAGAA-3'; LRP5, 5'-GGGTGGTGTCTATTTTGTGT-3' and 5'-CCGGAATGTTTGAAGAGTAG-3'; APC, 5'-CAGGCAAAACAAAATGTGGG-3' and 5'-CGCTTAGGACTTTGGGTTCC-3'; Asef2, 5'-TCTACTCGGGGGAGCTGACT-3' and 5'-CCTGCTTCCTCTGCAGTTCA-3'; GAPDH, 5' -CGCCACAGTTTCCCGGAGGG-3' and $5^{\prime}$-CCCTCCAAAATCAAGTGGGG-3'.

Cdc42 assay. Cdc42 activity was measured with a CDC42 activation kit (Upstate Biotechnology) according to the manufacturer's instructions. HUVECs were washed once with ice-cold PBS and lysed with lysis buffer containing $25 \mathrm{mM}$ HEPES, pH 7.5, $150 \mathrm{mM} \mathrm{NaCl}$, 1\% Igepal CA-630, $10 \mathrm{mM} \mathrm{MgCl} 2,1 \mathrm{mM}$ EDTA, $10 \%$ glycerol, $1 \mathrm{mM} \mathrm{Na}_{3} \mathrm{VO}_{4}, 10 \mu \mathrm{g} / \mathrm{ml}$ aprotinin, $10 \mu \mathrm{g} / \mathrm{ml}$ leupeptin, and $25 \mathrm{mM} \mathrm{NaF}$ for 15 minutes at $4^{\circ} \mathrm{C}$. Insoluble materials were removed by centrifugation. Five micrograms of PAK1-agarose beads, which specifically bind to active $\mathrm{Cdc} 42$, were added to the cell lysates and incubated for 1 hour at $4{ }^{\circ} \mathrm{C}$. Agarose beads were washed with lysis buffer 3 times and boiled in $2 \times$ Laemmli sample buffer. Samples were resolved by SDS-PAGE and immunoblotted with an anti-Cdc42 antibody.

Animal studies. All mice were maintained in a laminar airflow cabinet under specific pathogen-free conditions. All facilities were approved by the AAALAC (Association of Assessment and Accreditation of Laboratory Animal Care). All animal experiments were conducted under the institutional guidelines established for the Animal Core Facility at Yonsei University College of Medicine and were approved by the IACUC, Yonsei University.

Statistics. Data are presented as mean \pm SD or \pm SEM. Statistical comparisons between groups were performed using 1-way analysis of variance (ANOVA) followed by Student's $t$ test (1-tailed).

\section{Acknowledgments}

This work was supported by a National Research Laboratory grant (ROA-2007-000-20099-0); a Korea Biotech R\&D Group grant (F104AC010003-07A0301) from the Korean Science and Engineering Foundation (KOSEF) funded by the Ministry of Education \& Science Technology; a grant from the Korea Health 21 R\&D Project, Ministry of Health Welfare and Family Affairs, Republic of Korea (A085136); a Korea Research Foundation grant funded by the Korean government (KRF-2006-351-C00021 to J.K. Min); and a grant from the Korea Research Council of Fundamental Science \& Technology (Stem Cell Research Program to J.K. Min).

Received for publication February 4, 2010, and accepted in revised form February 16, 2011.

Address correspondence to: Young-Guen Kwon, Department of Biochemistry, College of Life Science and Biotechnology, Yonsei University, Seoul, 120-749, Republic of Korea. Phone: 82.2.2123.5697; Fax: 82.2.362.9897; E-mail: ygkwon@yonsei.ac.kr. 
1. Hanahan D, Folkman J. Patterns and emerging mechanisms of the angiogenic switch during tumorigenesis. Cell. 1996;86(3):353-364.

2. Coultas L, Chawengsaksophak K, Rossant J. Endothelial cells and VEGF in vascular development. Nature. 2005;438(7070):937-945.

3. Adams RH, Alitalo K. Molecular regulation of angiogenesis and lymphangiogenesis. Nat Rev Mol Cell Biol. 2007;8(6):464-478

4. Holderfield MT, Hughes CC. Crosstalk between vascular endothelial growth factor, notch, and transforming growth factor-beta in vascular morphogenesis. Circ Res. 2008;102(6):637-652.

5. Roca C, Adams RH. Regulation of vascular morphogenesis by Notch signaling. Genes Dev. 2007;21(20):2511-2524.

6. Siekmann AF, Covassin L, Lawson ND. Modulation of VEGF signalling output by the Notch pathway. Bioessays. 2008;30(4):303-313.

7. Gerhardt $\mathrm{H}$, et al. VEGF guides angiogenic sprouting utilizing endothelial tip cell filopodia. $J$ Cell Biol. 2003;161(6):1163-1177.

8. Carmeliet P, Tessier-Lavigne M. Common mechanisms of nerve and blood vessel wiring. Nature. 2005;436(7048):193-200.

9. Eichmann A, Makinen T, Alitalo K. Neural guidance molecules regulate vascular remodeling and vessel navigation. Genes Dev. 2005;19(9):1013-1021.

10. Larrivee B, et al. Activation of the UNC5B receptor by Netrin-1 inhibits sprouting angiogenesis. Genes Dev. 2007;21(19):2433-2447.

11. Hellstrom M, et al. Dll4 signalling through Notch1 regulates formation of tip cells during angiogenesis. Nature. 2007;445(7129):776-780.

12. Suchting $\mathrm{S}$, et al. The Notch ligand Delta-like 4 negatively regulates endothelial tip cell formation and vessel branching. Proc Natl Acad Sci US A. 2007;104(9):3225-3230.

13. Lobov IB, et al. Delta-like ligand 4 (DIl4) is induced by VEGF as a negative regulator of angiogenic sprouting. Proc Natl Acad Sci U S A. 2007; 104(9):3219-3224

14. Noguera-Troise I, et al. Blockade of Dll4 inhibits tumour growth by promoting non-productive angiogenesis. Nature. 2006;444(7122):1032-1037.

15. Thurston G, Noguera-Troise I, Yancopoulos GD The Delta paradox: DLL4 blockade leads to more tumour vessels but less tumour growth. Nat Rev Cancer. 2007;7(5):327-331.

16. Benedito R, et al. The notch ligands Dll4 and Jagged 1 have opposing effects on angiogenesis. Cell. 2009;137(6):1124-1135.

17. Zerlin M, Julius MA, KitajewskiJ. Wnt/Frizzled signaling in angiogenesis. Angiogenesis. 2008;11(1):63-69.

18. Franco CA, Liebner S, Gerhardt H. Vascular morphogenesis: a Wnt for every vessel? Curr Opin Genet Dev. 2009;19(5):476-483.

19. Lobov IB, et al. WNT7b mediates macrophageinduced programmed cell death in patterning of the vasculature. Nature. 2005;437(7057):417-421.

20. Clevers H. Eyeing up new Wnt pathway players. Cell. 2009;139(2):227-229.

21. Xu Q, et al. Vascular development in the retina and inner ear: control by Norrin and Frizzled-4, a high-affinity ligand-receptor pair. Cell. 2004; 116(6):883-895.

22. Glinka A, Wu W, Delius H, Monaghan AP, Blumen- stock C, Niehrs C. Dickkopf-1 is a member of a new family of secreted proteins and functions in head induction. Nature. 1998;391(6665):357-362.

23. Kawano Y, Kypta R. Secreted antagonists of the Wnt signalling pathway. J Cell Sci. 2003; 116(pt 13):2627-2634.

24. Mao B, et al. LDL-receptor-related protein 6 is a receptor for Dickkopf proteins. Nature. 2001; 411(6835):321-325

25. Cao R, et al. Angiogenic synergism, vascular stability and improvement of hind-limb ischemia by a combination of PDGF-BB and FGF-2. Nat Med. 2003; 9(5):604-613.

26. Limbourg A, KorffT, Napp LC, Schaper W, Drexler $\mathrm{H}$, Limbourg FP. Evaluation of postnatal arteriogenesis and angiogenesis in a mouse model of hindlimb ischemia. Nat Protoc. 2009;4(12):1737-1746.

27. Brown MD, Cornejo BJ, Kuhn TB, Bamburg JR. $\mathrm{Cdc} 42$ stimulates neurite outgrowth and formation of growth cone filopodia and lamellipodia. J Neurobiol. 2000;43(4):352-364.

28. Hamann MJ, Lubking CM, Luchini DN, Billadeau DD. Asef2 functions as a Cdc42 exchange factor and is stimulated by the release of an autoinhibitory module from a concealed C-terminal activation element. Mol Cell Biol. 2007;27(4):1380-1393.

29. Niehrs C. Function and biological roles of the Dickkopf family of Wnt modulators. Oncogene. 2006; 25(57):7469-7481.

30. Wu W, Glinka A, Delius H, Niehrs C. Mutual antagonism between dickkopf1 and dickkopf2 regulates Wnt/beta-catenin signalling. Curr Biol. 2000;10(24):1611-1614

31. Jakobsson L, Domogatskaya A, Tryggvason K, Edgar D, Claesson-Welsh L. Laminin deposition is dispensable for vasculogenesis but regulates blood vessel diameter independent of flow. FASEB $J$. 2008;22(5):1530-1539.

32. Dixelius J, Jakobsson L, Genersch E, Bohman S, Ekblom P, Claesson-Welsh L. Laminin-1 promotes angiogenesis in synergy with fibroblast growth factor by distinct regulation of the gene and protein expression profile in endothelial cells. J Biol Chem. 2004; 279(22):23766-23772

33. Katoh M. WNT antagonist, DKK2, is a Notch signaling target in intestinal stem cells: augmentation of a negative regulation system for canonical WNT signaling pathway by the Notch-DKK2 signaling loop in primates. Int J Mol Med. 2007;19(1):197-201.

34. Bayless KJ, Davis GE. The Cdc42 and Rac1 GTPases are required for capillary lumen formation in three-dimensional extracellular matrices. J Cell Sci. 2002;115(pt 6):1123-1136.

35. Kamei M, Saunders WB, Bayless KJ, Dye L, Davis GE, Weinstein BM. Endothelial tubes assemble from intracellular vacuoles in vivo. Nature. 2006; 442(7101):453-456

36. Mi K, Johnson GV. Role of the intracellular domains of LRP5 and LRP6 in activating the Wnt canonical pathway. J Cell Biochem. 2005;95(2):328-338.

37. Tamai K, et al. LDL-receptor-related proteins in Wnt signal transduction. Nature. 2000; 407(6803):530-535.

38. Holmen SL, Salic A, Zylstra CR, Kirschner MW, Williams BO. A novel set of Wnt-Frizzled fusion proteins identifies receptor components that activate beta-catenin-dependent signaling.J Biol Chem.
2002;277(38):34727-34735

39. Katoh M. WNT signaling pathway and stem cell signaling network. Clin Cancer Res. 2007; 13(14):4042-4045.

40. Kawasaki Y, Sagara M, Shibata Y, Shirouzu M, Yokoyama S, Akiyama T. Identification and characterization of Asef2, a guanine-nucleotide exchange factor specific for Rac1 and Cdc42. Oncogene. 2007; 26(55):7620-7267.

41. Schlessinger K, McManus EJ, Hall A. Cdc42 and noncanonical Wnt signal transduction pathways cooperate to promote cell polarity. J Cell Biol. 2007; 178(3):355-361.

42. Ye X, et al. Norrin, frizzled-4, and Lrp5 signaling in endothelial cells controls a genetic program for retinal vascularization. Cell. 2009;139(2):285-298.

43. Goodwin AM, D'Amore PA. Wnt signaling in the vasculature. Angiogenesis. 2002;5(1-2):1-9.

44. Phng LK, et al. Nrarp coordinates endothelial Notch and Wnt signaling to control vessel density in angiogenesis. Dev Cell. 2009;16(1):70-82.

45. Li X, et al. Dkk2 has a role in terminal osteoblast differentiation and mineralized matrix formation. Nat Genet. 2005;37(9):945-952.

46. Mukhopadhyay M, et al. Dickkopf1 is required for embryonic head induction and limb morphogenesis in the mouse. Dev Cell. 2001;1(3):423-434.

47. Untergasser $\mathrm{G}$, et al. The Dickkopf-homolog 3 is expressed in tumor endothelial cells and supports capillary formation. Int J Cancer. 2008; 122(7):1539-1547.

48. Carmeliet P. VEGF gene therapy: stimulating angiogenesis or angioma-genesis? Nat Med. 2000; 6(10):1102-1103.

49. Celletti FL, Waugh JM, Amabile PG, Brendolan A, Hilfiker PR, Dake MD. Vascular endothelial growth factor enhances atherosclerotic plaque progression. Nat Med. 2001;7(4):425-429.

50. Epstein SE, Kornowski R, Fuchs S, Dvorak HF. Angiogenesis therapy: amidst the hype, the neglected potential for serious side effects. Circulation. 2001; 104(1):115-119.

51. Hendel RC, et al. Effect of intracoronary recombinant human vascular endothelial growth factor on myocardial perfusion: evidence for a dose-dependent effect. Circulation. 2000;101(2):118-121.

52. Jaffe EA, Nachman RL, Becker CG, Minick CR. Culture of human endothelial cells derived from umbilical veins. Identification by morphologic and immunologic criteria. J Clin Invest. 1973; 52(11):2745-2756.

53. Min JK, et al. Receptor activator of nuclear factor (NF)-kappaB ligand (RANKL) increases vascular permeability: impaired permeability and angiogenesis in eNOS-deficient mice. Blood. 2007; 109(4):1495-1502.

54. Chan-Ling T. Glial, vascular, and neuronal cytogenesis in whole-mounted cat retina. Microsc Res Tech. 1997;36(1):1-16.

55. Kang Y, Choi M, Lee J, Koh GY, Kwon K, Choi C. Quantitative analysis of peripheral tissue perfusion using spatiotemporal molecular dynamics. PLoS One. 2009;4(1):e4275.

56. Song H, et al. Tissue transglutaminase is essential for integrin-mediated survival of bone marrow-derived mesenchymal stem cells. Stem Cells. 2007;25(6):1431-1438. 